\title{
Toward high resolution mapping of patterned ground with vegetation in Spitsbergen using a UAV
}

\author{
Jaeyong Lee ${ }^{\mathrm{a}, *}$, Takashi Oguchi ${ }^{\text {a, b }}$ \\ a Graduate School of Frontier Sciences, The University of Tokyo, Japan, lee@csis.u-tokyo.ac.jp \\ ${ }^{b}$ Center for Spatial Information Science, The University of Tokyo, Japan, oguchi@csis.u-tokyo.ac.jp \\ * Corresponding author
}

Keywords: Periglacial terrain, Spitsbergen, RTK-GNSS, Patterned ground

\section{Abstract:}

We focused on technical methods for mapping of periglacial terrain in Spitsbergen, Svalbard. In polar regions, there are permafrost areas with patterned ground formed by physical movement of the surface layer of permafrost, reflecting the characteristics of climate and topography. Also, mosses and lichens covering the topsoil are likely to be related to climate and topography. Since patterned ground is generated slowly over a long period, it is highly sensitive to changes in the polar environment. Vegetation is the main nutrient source for polar animals. Therefore, understanding the status of vegetation is important for monitoring and managing the polar environment in general.
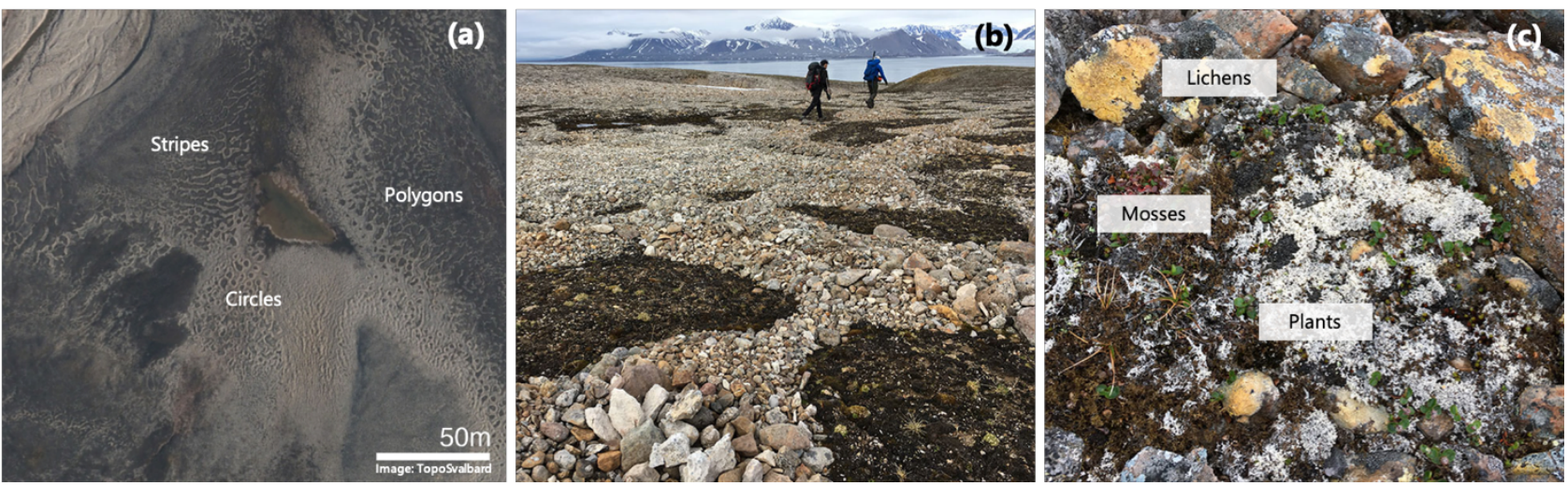

Figure 1. Images of periglacial features in Spitsbergen. (a) Patterned ground in Ny-Alesund. (b) Polygonal patterned ground. (c) Vegitation on permafrost in Ny-Alesund.
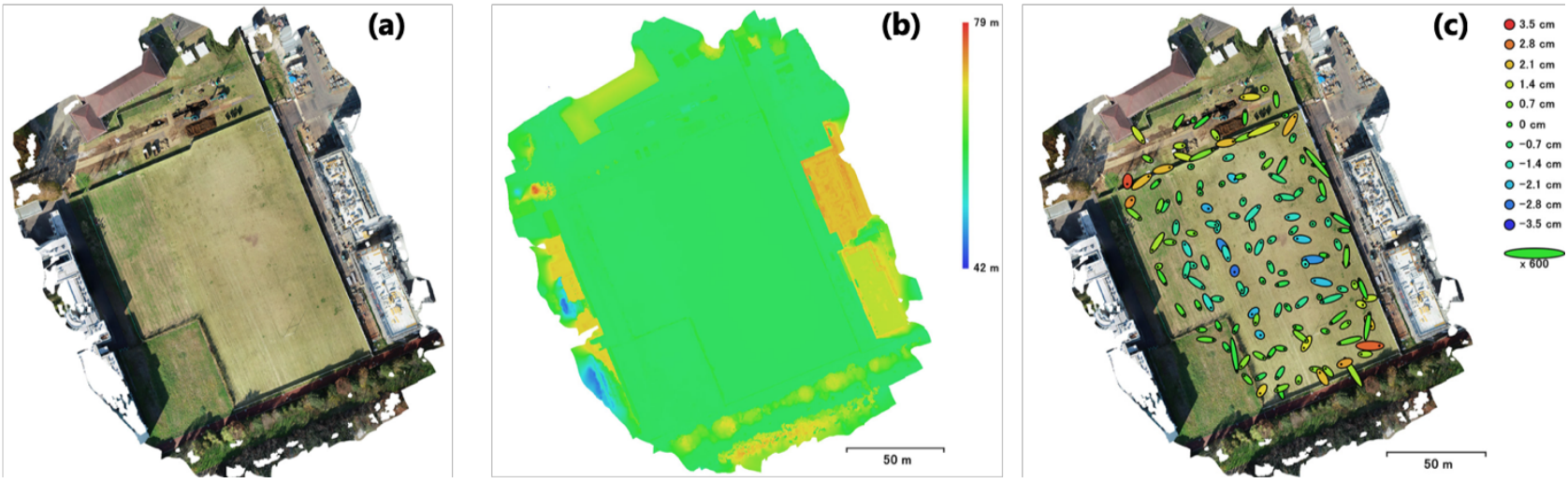

Figure 2. UAV test with RTK-GNSS in Kashiwanoha. (a) Orthomosaic image. Resolution: 1.62cm/px. (b) DEM image. Resolution: $6.48 \mathrm{~cm} / \mathrm{px}$. (c) RMSE of the image.

To address the issues above, accurate high-resolution topographic maps are important for tracking and predicting future topographic and ecosystem changes. However, conventional satellite images and aerial images do not have sufficient resolution for this purpose. Accordingly, it is necessary to collect high-resolution topographic data and images with a multi-copter UAV and the SfM-MVS technique.

In this study, we tried to develop methods such as UAV operation with RTK-level accuracy, a stabilized pole camera, and a 360-degrees camera for field work in the Arctic to produce detailed polar topographical maps. During flight tests 
in Longyearbyen, Svalbard and Kashiwanoha, Japan, our UAV showed good flight stability, and a UAV flight test with RTK-GNSS resulted in an RMSE value of $1.47 \mathrm{~cm}$. To ensure stable camera shots even in the rugged surface environment where walking is difficult, we made a pole camera with the GoPro and Gimbal system, which led to good stability and high quality photographs. 